\title{
Risk of urothelial bladder cancer in Lynch syndrome is increased, in particular among MSH2 mutation carriers
}

\author{
R S van der Post, ${ }^{1,2}$ L A Kiemeney, ${ }^{3,4,5} \mathrm{M} \mathrm{J}$ L Ligtenberg, ${ }^{1,2} \mathrm{~J}$ A Witjes, ${ }^{4}$ \\ C A Hulsbergen-van de Kaa, ${ }^{2}$ D Bodmer, ${ }^{1}$ L Schaap, ${ }^{1}$ C M Kets, ${ }^{1}$ \\ J H J M van Krieken, ${ }^{2} \mathrm{~N}$ Hoogerbrugge ${ }^{1,6}$
}

'Department of Human Genetics, Radboud University Nijmegen Medical Centre, Nijmegen, the Netherlands ${ }^{2}$ Department of Pathology, Radboud University Nijmegen Medical Centre, Nijmegen, the Netherlands

${ }^{3}$ Department of Epidemiology, Biostatistics and HTA, Radboud University Nijmegen Medical Centre, Nijmegen, the Netherlands

${ }^{4}$ Department of Urology, Radboud University Nijmegen Medical Centre, Nijmegen, the Netherlands

${ }^{5}$ Comprehensive Cancer Centre East, Nijmegen, the Netherlands ${ }^{6}$ Department of Medical Oncology, Radboud University Nijmegen Medical Centre, Nijmegen, the Netherlands

\section{Correspondence to}

Professor Nicoline

Hoogerbrugge, 849 Human Genetics, Radboud University Nijmegen Medical Centre, Postbox 9101, 6500 HB Nijmegen, The Netherlands; n.hoogerbrugge@antrg.umcn.nl

Received 11 January 2010 Revised 9 February 2010 Accepted 11 February 2010

\section{(2) UN OCKKA}

This paper is freely available online under the BMJ Journals unlocked scheme, see http:// jmg.bmj.com/site/about/ unlocked.xhtml

\begin{abstract}
Background Colorectal, endometrial and upper urinary tract tumours are characteristic for Lynch syndrome (hereditary non-polyposis colon carcinoma, HNPCC). The aim of the present study was to establish whether carriers of mutations in mismatch repair genes MLH1, MSH2 or MSH6 are at increased risk of urinary bladder cancer.

Methods Carriers and first degree relatives of 95 families with a germline mutation in the MLH1 $(\mathrm{n}=26)$, MSH2 $(n=43)$, or MSH6 $(n=26)$ gene were systematically questioned about the occurrence of carcinoma. The cumulative risk of cancer occurring before the age of 70 years (CR70) was compared to the CR70 of the general Dutch population. Microsatellite instability (MSI) testing and/or immunohistochemistry (IHC) for mismatch repair proteins was performed on bladder tumour tissue.
\end{abstract}

Results Bladder cancer was diagnosed in 21 patients (90\% men) from 19 Lynch syndrome families (2 MLH1, $15 \mathrm{MSH}$, and $4 \mathrm{MSH}$ ). CR70 for bladder cancer was $7.5 \%(95 \% \mathrm{Cl} 3.1 \%$ to $11.9 \%)$ for men and $1.0 \%(95 \% \mathrm{Cl}$ $0 \%$ to $2.4 \%)$ for women, resulting in relative risks for mutation carriers and first degree relatives of $4.2195 \% \mathrm{Cl}$ 2.2 to 7.2$)$ for men and $2.2(95 \% \mathrm{Cl} 0.3$ to 8.0$)$ for women. Men carrying an MSH2 mutation and their first degree relatives were at highest risks: CR70 for bladder and upper urinary tract cancer being $12.3 \%(95 \% \mathrm{Cl}$ $4.3 \%$ to $20.3 \%$ ) and $5.9 \%(95 \% \mathrm{Cl} 0.7 \%$ to $11.1 \%)$. Bladder cancer tissue was MSI positive in 6/7 tumours and loss of IHC staining was found in 14/17 tumours, indicating Lynch syndrome aetiology.

Conclusion Patients with Lynch syndrome carrying an MSH2 mutation are at increased risk of urinary tract cancer including bladder cancer. In these cases surveillance should be considered.

\section{INTRODUCTION}

Lynch syndrome, previously called hereditary nonpolyposis colon carcinoma (HNPCC), is caused by a germline mutation in one of the mismatch repair (MMR) genes $M L H 1, M S H 2, M S H 6$ and PMS2. It results in a large increase in spontaneous mutations and thus has a direct oncogenic effect. Besides the high risk of developing colorectal carcinomas of 10-80\%, Lynch syndrome family members are at increased risk of developing several extra-colonic cancers and tumours at a relatively young age: endometrial cancer, carcinomas of the ovary, small bowel and biliary tract cancer, seba- ceous gland tumours and urothelial carcinomas (UC) of the upper urinary tract. ${ }^{1-10}$ The lifetime risk of upper urinary tract cancer in Lynch syndrome varies in different studies from $0.4-20 \% .{ }^{1} \quad 2 \quad 6 \quad 9 \quad 11-18$ Microsatellite instability (MSI) is present in these urothelial carcinomas of the upper urinary tract. ${ }^{19} 20$

A study based on the Swedish family cancer database, quantifying the occurrence of UC in families with at least four generations, showed that families fulfilling the Bethesda criteria ${ }^{21}$ have an increased risk of cancers in the ureter, but not in the urinary bladder. ${ }^{18}$ It was concluded that in families at risk for Lynch syndrome, UC of the bladder occurs at a frequency comparable to that in the general population. The study did not report results which were stratified by type of mutation. On the contrary, in a study by Geary et al, bladder cancer was more common in MSH2 mutation families than expected in the general population, the relative risk (RR) being $3.6(p=0.001) .{ }^{16}$ Cumulative risks were not presented. In their study every case of bladder cancer was accompanied by cancer of the ureter in the family. For that reason, the authors concluded that the risk of bladder cancer was increased only in families with ureter cancer.

In addition to morphologic resemblance, sporadic urothelial cell cancers of the renal pelvis, ureter and bladder share the most important risk factors and molecular genetic aberrations; it is therefore remarkable that the risk of bladder cancer does not appear to have increased in Lynch syndrome families, while the risk of upper urinary tract cancer has. The aim of the present study was to establish whether patients with Lynch syndrome are at increased risk of cancer of the urinary bladder.

\section{PATIENTS AND METHODS}

\section{Patient population}

From 95 Lynch syndrome families, we selected all carriers of a germline mutation in the MSH2, MLH1 or MSH6 gene, who had been seen and registered at the Department of Human Genetics of the Radboud University Nijmegen Medical Centre between 1996 and November 2008, and all their first degree relatives-a total of 627 men and 617 women. Information on mutation carriers and their first degree relatives was systematically collected by postal questionnaires and telephone calls with contact persons when data were outdated for more than 1 year. In each family, one to six such persons 
Table 1 Life table cumulative risks of cancers before the age of $70(\%)$

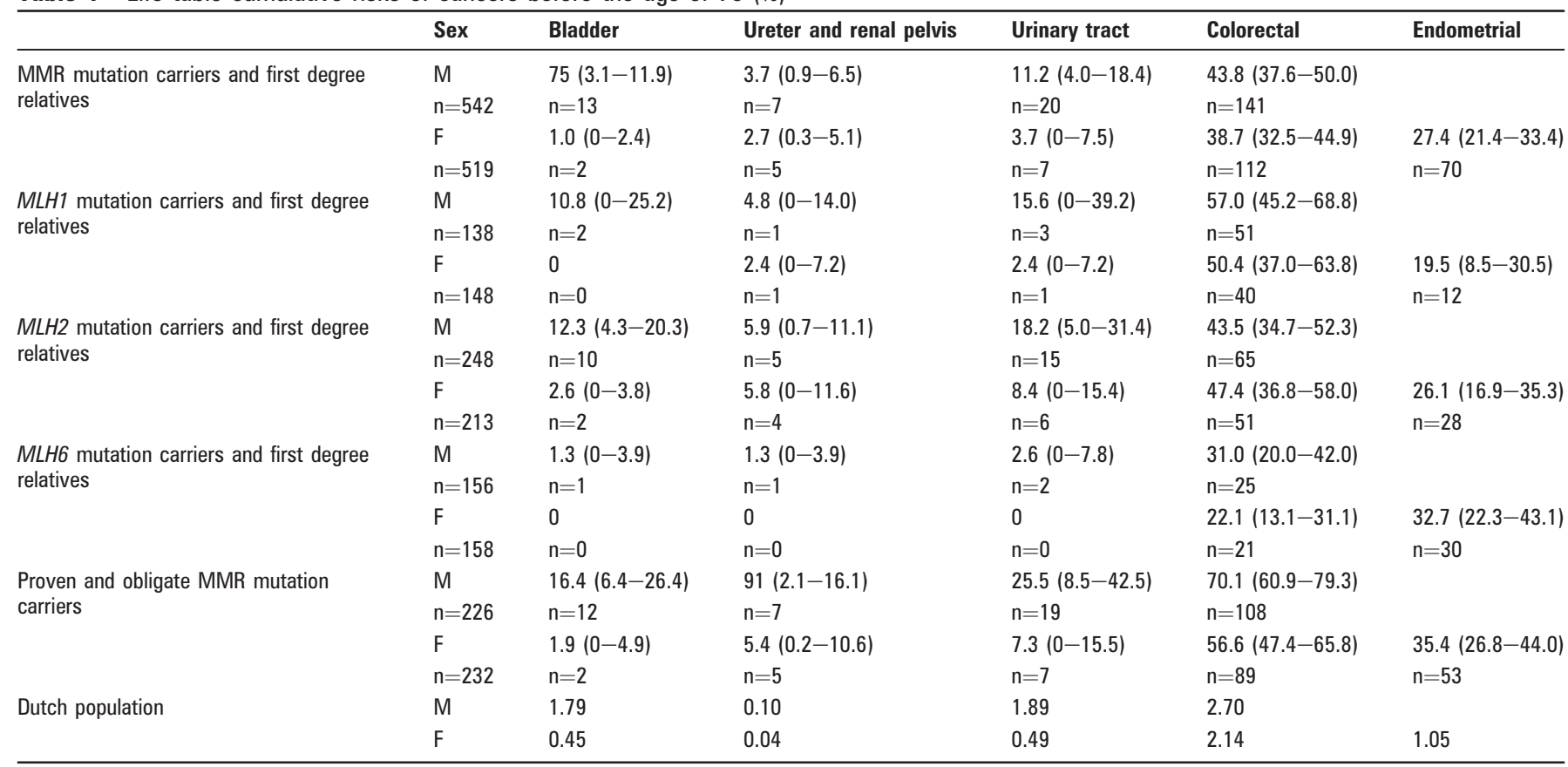

F, female; M, male; MMR, mismatch repair.

were contacted in order to obtain up-to-date information on the occurrence of carcinoma in mutation carriers and their first degree relatives. First degree relatives with MMR gene mutation negative tests were excluded. All diagnoses of UC carcinoma were verified and confirmed by review of pathology reports or medical reports.

\section{Statistical analysis}

We calculated follow-up time for each family member with the date of birth as starting point until the dates of last contact, death, or diagnosis of cancer, whichever came first. Kaplan-Meier (KM) survival analyses were used to calculate the cumulative risk (plus SE) of cancer until specific ages. We chose the age of 70 as censuring age because the number of patients being at risk after that age is small. SPSS version 16.0 was used for KM analyses. For reference, we used life table cancer risk estimates as reported by the Dutch Cancer Registry (http:// www.ikcnet.nl), based on cancer incidence and population demographics in $2003{ }^{22}$ The life table risks of urinary tract cancer are almost identical to those reported by SEER (Surveillance Epidemiology and End Results) for whites in the USA (http://seer.cancer.gov). Relative risks of cancer among specific groups compared to the Dutch reference risks were defined as the ratio between observed and expected numbers of tumours before the age of 70 years. Exact, 95\% confidence interval (CIs) of the RRs were calculated using the publicly available OpenEpi software (http://www.openepi.com).

\section{Histology and molecular analysis}

After written informed consent, histology reports and tissue blocks of UC of the bladder, ureter or renal pelvis were collected. Clinicopathological features of the urothelial cell cancers were reviewed by two experienced pathologists using haematoxylin and eosin (H\&E) slides. The following parameters were scored: (1) tumour differentiation according to the World Health Organization 2004 grading system; (2) T stage (TNM 2002); (3) growth pattern: papillary or solid; (4) presence of tumour infiltrating lymphocytes (TILs): absent, moderate or dense.

For MSI analysis, areas of the formalin fixed and paraffin embedded tissues containing either tumour cells (at least 30\%) or normal cells were marked and material from these areas was isolated separately using a lysis buffer and a protein precipitation solution (Purogene, Gentra systems, Minneapolis, Minnesota, USA). PCR of the markers D2S123, D5S346, D17S250, BAT25, BAT26 and BAT40 was performed using standard conditions in the presence of a fluorescently labelled primer. GeneScan analysis was performed on an ABI373A, ABI3100 or ABI3700 apparatus (PE Biosystems, Foster City, California, USA). A tumour was considered MSI positive when at least two of these standard set of markers, or $30 \%$ of an extended set, showed instability. ${ }^{23}$

Immunohistochemistry (IHC) was performed on formalin fixed, paraffin embedded tissues. Slides were stained with antibodies against MLH1 (Pharmingen code: 51-1327gr), PMS2 (Pharmingen code: 556415), MSH2 (Oncogene Research Products code: NA26) and MSH6 (Transduction Laboratories code: G70220). Staining patterns of MMR proteins were evaluated using normal epithelial, stromal and inflammatory cells as internal controls. Stained slides were scored as: (1) positivethat is, showing nuclear staining in at least some tumour cells; (2) negative-that is, no staining of the tumour with a positive internal control; or (3) not assessable-that is, insufficient technical quality to provide an unambiguous result despite repeated assays. ${ }^{24} 25$ As a verification five anonymous sporadic cancers of the bladder were taken at random from the files of the department of pathology.

\section{RESULTS}

Members of 95 Lynch syndrome families diagnosed by a germline mutation in MLH1 ( $\mathrm{n}=26), M S H 2(\mathrm{n}=43)$ or MSH6 $(\mathrm{n}=26)$ were questioned by contact persons for occurrence of cancer such as UC of the bladder, ureter or renal pelvis. The total cohort of 1244 


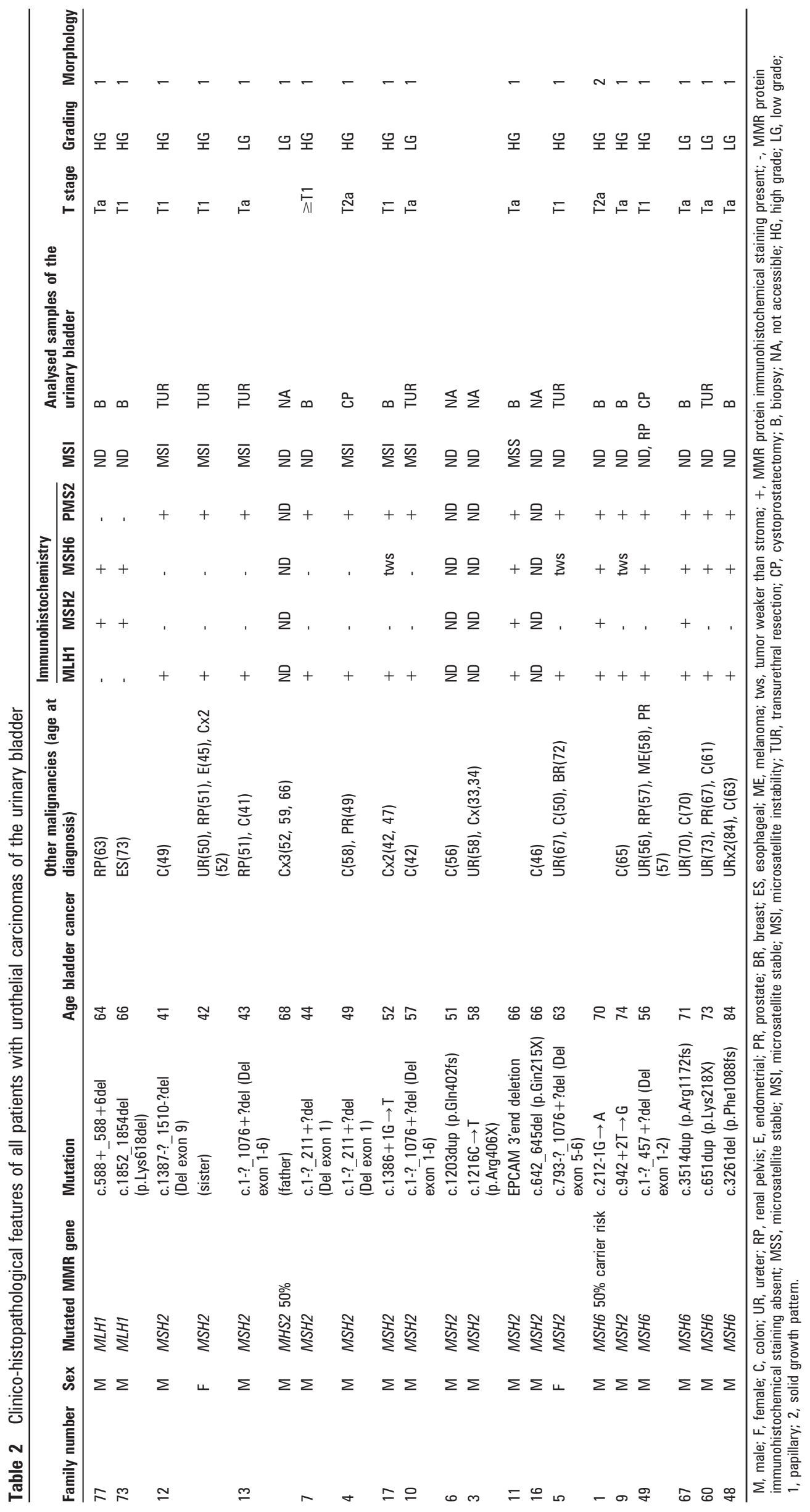


Figure 1 Absence of nuclear immunohistochemical staining of MLH1 protein $(\mathrm{A})$ and presence of MSH2 protein (B) in urothelial carcinomas (UC) of the urinary bladder (original magnifications, $250 \times$ ) of a patient carrying a germline $\mathrm{MLH} 1$ mutation. Note in figure $1 \mathrm{~A}$ the presence of nuclear staining in normal mucosa and absence in carcinoma.
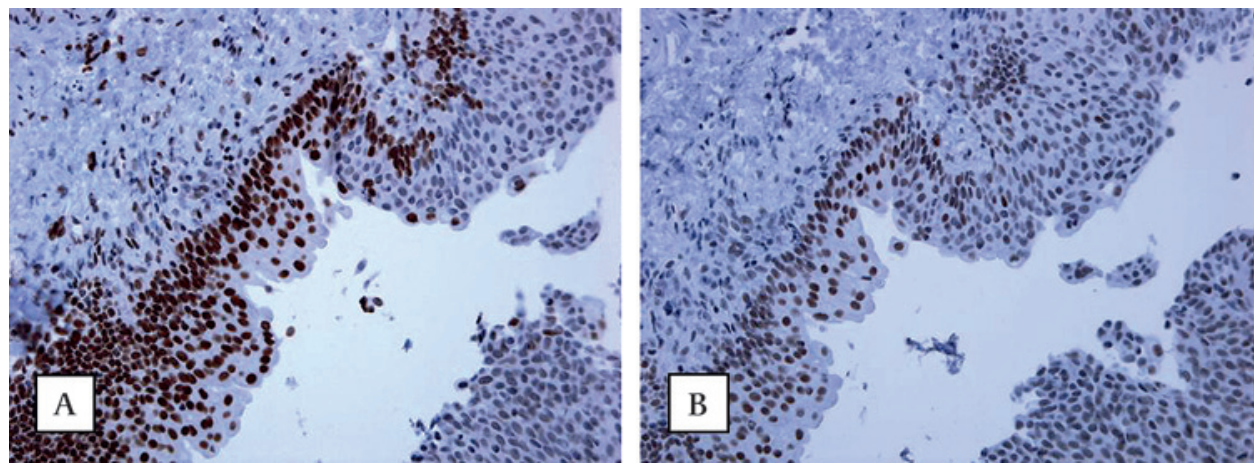

persons consisted of 406 proven mutation carriers (individuals with a pathogenic mutation on germline mutation analysis) and 838 first degree relatives. The latter group consisted of 111 obligate mutation carriers (concluded because of their position in the pedigree in relation to relatives tested positive for a mutation) and 727 persons at $50 \%$ risk to be mutation carriers. In 22 families, at least one $(n=27)$ confirmed mutation carrier or first degree relative of a mutation carrier was diagnosed with UC of the urinary bladder, ureter or renal pelvis. In two additional MSH2 families, the patient with UC of the bladder was not a first but a second degree relative of the mutation carrier diagnosed. Second degree relatives were not included in the KM risk analysis but the two second degree relatives with UC were included in the histopathology study. UC of the bladder was diagnosed in 21 patients from 19 Lynch syndrome families, the majority (71\%) coming from MSH2 families (15 MSH2, two MLH1, and four MSH6); 19 out of $21(90 \%)$ were men. Two patients with bladder cancer were at $50 \%$ risk of being an $M S H 2$ mutation carrier, but could not be tested. Bladder cancer was diagnosed at an average age of $60 \pm 12$ years (range 41-84 years), which is approximately 10 years younger than the average age of sporadic bladder cancer in the Netherlands.

The cumulative risk of bladder cancer until the age of 70 (CR70) in all MMR mutation carriers and their first degree relatives was $7.5 \%$ (95\% CI $3.1 \%$ to $11.9 \%$ ) for men and $1.0 \%$ ( $95 \%$ CI $0 \%$ to $2.4 \%$ ) for women (table 1$)$. The corresponding CR70 for the Dutch population is $1.8 \%$ for men and $0.5 \%$ for women. The RR for carriers of any MMR mutation, as compared to the general Dutch population, was 4.2 (95\% CI 2.2 to $7.2, p<0.001)$ for men and 2.2 (95\% CI 0.3 to 8.0, $p=0.5)$ for women (table 1). MSH2 mutation carriers and first degree relatives showed the highest risk of bladder cancer: CR70 is $12.3 \%$ (95\% CI $4.3 \%$ to $20.3 \%$ ) in men and $2.6 \%$ (95\% CI $0 \%$ to $3.9 \%)$ for women. The RR of bladder cancer in carriers of an MSH2 mutation and their first degree relatives, as compared to the general Dutch population, was 7.0 (95\% CI 3.4 to $13.0, p<0.001)$ for men and 5.8 (95\% CI 0.5 to 16.1, $\mathrm{p}=0.15$ ) for women. The overall CR70 risk for urinary tract cancer, including the bladder, in $\mathrm{MSH} 2$ mutation carriers and first degree relatives was $18.2 \%$ (95\% CI $5.0 \%$ to $31.4 \%$ ) in men and $8.4 \%$ (95\% CI $0 \%$ to $15.4 \%$ ) in women (table 1).

Two or more primary urinary tract cancers, of which one was in the bladder, were diagnosed in nine of all 21 patients with bladder cancer; in six patients these two cancers were diagnosed synchronously or within 1 year. The remaining three patients, with a metachronous combination of bladder and upper urinary tract cancer, had their bladder cancer diagnosed earlier in life than the upper urinary tract cancer. Exclusive upper urinary tract cancer was diagnosed in eight patients from seven Lynch syndrome families, with $63 \%$ caused by $M S H 2$ (five $M S H 2$, two MLH1, and one MSH6). The CR70 of colorectal cancer for confirmed MMR mutation carriers was $63.2 \%$ (95\% CI $56.6 \%$ to $69.8 \%)$ and the CR70 of endometrial cancer was $35.4 \%(95 \% \mathrm{CI}$ $26.8 \%$ to $44.0 \%$ ) (table 1 ).

Bladder cancers from germline MSH2 mutation carriers were tested for mismatch repair deficiency: MSI was present in bladder tumour DNA from six out of seven cases, and IHC staining of MSH2 protein was absent in nine out of 11 cases, indicating mismatch repair deficiency (figure 2, table 2). Additionally, IHC staining of MLH1 or MSH6 proteins was absent in five out of six bladder carcinomas from $M L H 1$ or $M S H 6$ germline mutation carriers, respectively (figure 1, table 2). Three bladder tumours were identified having normal IHC staining and one tumour was MSS. As a control, IHC of five sporadic bladder carcinomas showed normal staining of all four MMR system proteins. No typical histological characteristics were observed in the bladder carcinomas when compared with sporadic bladder carcinomas (table 2).
Figure 2 Absence of nuclear immunohistochemical staining of $\mathrm{MSH} 2$ protein $(A)$ and presence of MLH1 protein $(B)$ in urothelial cell carcinoma of the urinary bladder (original magnifications, $400 \times$ ) of a patient carrying a germline $\mathrm{MSH} 2$ mutation. Observe the nuclear staining in stromal cells as an internal control.
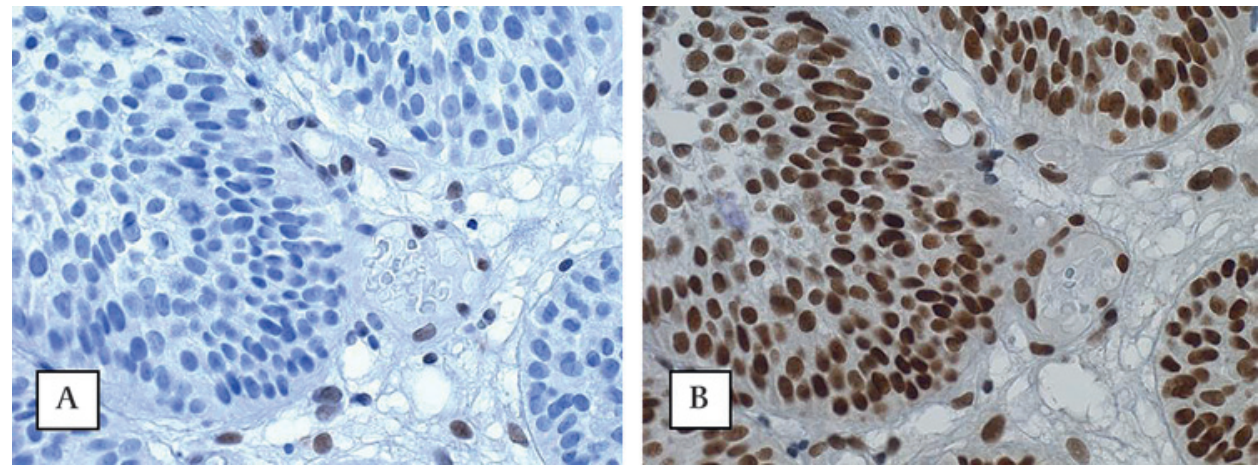


\section{DISCUSSION}

This study indicates an increased risk of urothelial cancer of both the urinary bladder and the upper urinary tract (ureter and renal pelvis) in patients with Lynch syndrome carrying a germline MSH2 mutation. Furthermore, this study indicates that cancer of the urinary bladder, ureter and renal pelvis is also, though rarely, associated with $M S H 6$ or $M L H 1$ mutations. A causal relation between MSH2 deficiency and bladder cancer is likely: in the first place, because bladder cancers in these families often show MSI and/or absence of IHC staining of the MSH2 protein, just like upper urothelial tract cancer and colorectal cancer; in the second place, because of the presence of two MSH2 mutation families, each of which contained two first degree family members with bladder cancer, and with three of the bladder cancers diagnosed under the age of 50 (as illustrated in figure 3). It is interesting that especially $M S H 2$ mutation carriers are at increased risk of urothelial cancer, as observed in this cohort and in previous studies. ${ }^{2} 1216$ The diversity in the function of the MSH2, MLH1 and MSH6 protein might be responsible for the variation in cancer risk. Environmental factors (eg, smoking status) may also affect the urologic tract cancer occurrence rates, but we do not have the necessary information to determine if this might contribute to the differences.

In eight out of 21 patients with bladder cancer, this was their first cancer diagnosis, whereas at this stage five of them developed another Lynch syndrome associated cancer at an older age. Therefore, early diagnosis of Lynch syndrome may prevent development of a second primary cancer, especially colorectal cancer (CRC) by regular colonoscopy with polypectomy. ${ }^{26}$ The diagnosis of Lynch syndrome in healthy relatives may lead to prevention or early detection of cancer, which improves the prognosis. ${ }^{26}$ Thus bladder cancer, just like upper urothelial tract cancer, can be added to the Bethesda criteria ${ }^{21}$ and the Amsterdam II criteria, ${ }^{27}$ and lead to the clinical suspicion of Lynch syndrome. The occurrence of bladder cancer can be used in family history taking and molecular diagnostics to identify the families that are at risk of Lynch syndrome.
Cumulative risks of colorectal and endometrial cancer are within the ranges published by other studies. ${ }^{2-58132829}$ Bladder cancer risk observed in our cohort was significantly higher than that observed in previous studies. ${ }^{6} \quad 9 \quad 12 \quad 16 \quad 18$ These studies differed from our study by: (1) type of risk that was calculated; (2) by type of population; and (3) whether or not the type of mutation was distinguished. The data from these studies are given in table 3 . Additionally the discrepancy in bladder cancer risk between our study and other studies may result from our systematic data collection approach (obtaining up-to-date information). This led to the discovery of nine new cases of bladder carcinoma, previously unrevealed with the standard procedure of a clinical geneticist taking the family history.

Considering the high risk of urothelial tract cancer in MSH2 mutation carriers, a surveillance programme needs to be developed. At present various recommendations have been published. The present European guidelines for families with an MMR mutation include ultrasound and urinalysis every 1-2 years with patients from the age of 30 to 35 only in cases where upper urinary tract cancer runs in the family (two or more cases of UC). ${ }^{11}$ The American guidelines include urinalysis with cytology every $1-2$ years with patients from the age of 25 to 35 for all family members with Lynch syndrome. ${ }^{30}$ Watson et al proposed (unspecified) surveillance of patients starting with the age of 50, especially for families that carry mutations in $\mathrm{MSH} \mathrm{H}^{12}$ Although cytology is the superior marker in terms of specificity, ${ }^{31}$ Myrhoy et al showed that the sensitivity of urine cytology in diagnosing asymptomatic upper urinary tract cancer in Lynch syndrome is approximately 30\%. Therefore, cytology only is not a proper method of surveillance. ${ }^{32}$ The most important biomarker of urothelial cancer is macro- or microscopically haematuria, which occurs in $85 \%$ of patients with bladder cancer. ${ }^{33}$ Consequently, Koornstra et al recommend annual surveillance for haematuria, by urinary dipstick, of all patients with Lynch syndrome, beginning at the age of 45 to $50 .^{34}$ The recent use of sensitive transducers has improved imaging of the upper urinary tract and bladder by
Figure 3 Pedigree of a Lynch syndrome family with two MSH2 mutation carriers with urinary bladder cancer. CRC, colorectal cancer.

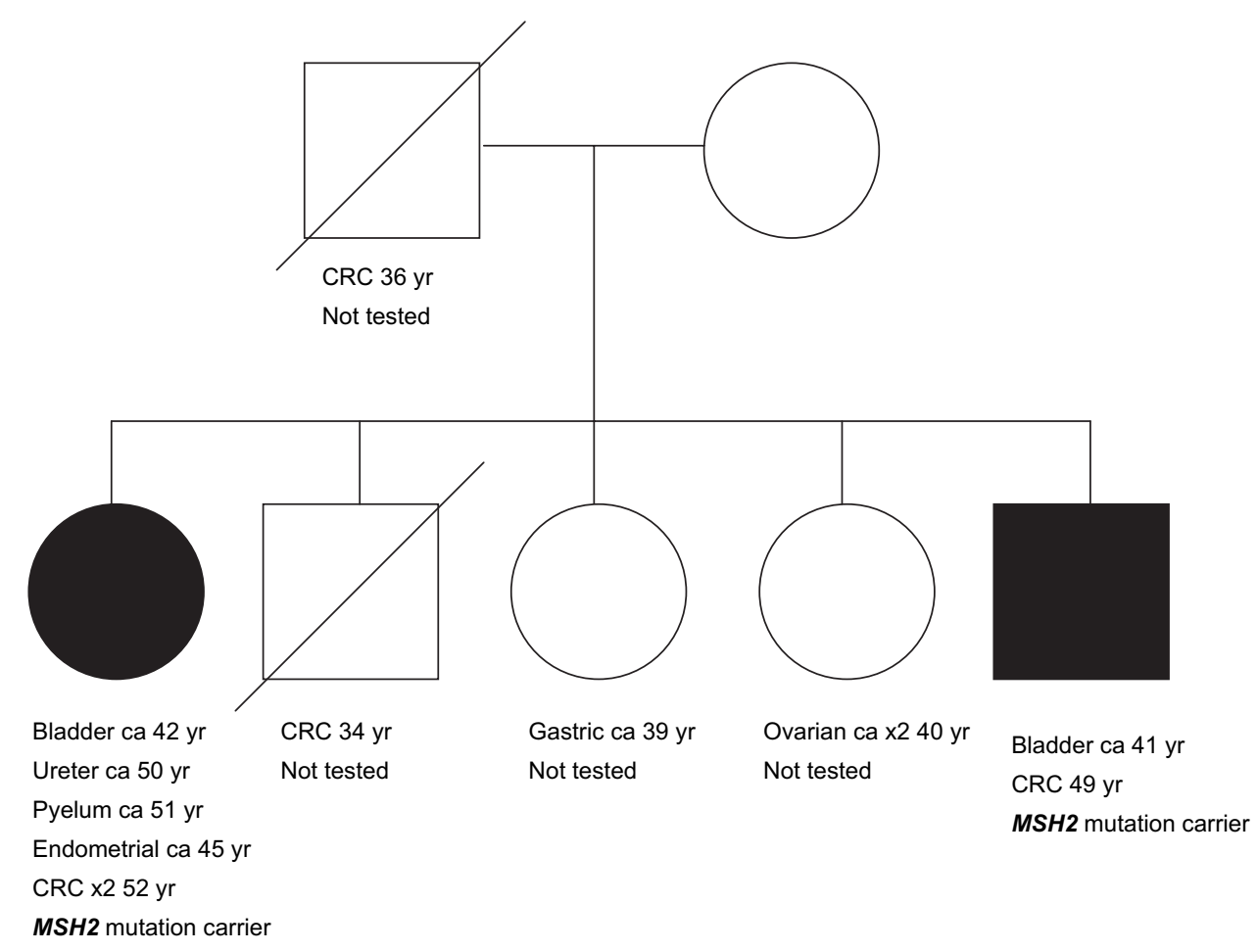


Recommendations for urothelial carcinomas surveillance in Lynch syndrome

1. Surveillance with a combination of ultrasound of the bladder and upper urinary tract, urinary cytology and sediment.

2. In every MSH2 mutation carrier

3. From age 40 and up

4. Performed every $1-2$ years

ultrasonography. It was shown to be as accurate in the detection of renal masses and bladder filling defects as intravenous urography and computed tomography scanning. ${ }^{35}$

Further studies are needed to develop an optimum early detection strategy concerning the appropriate interval, methods to be used, and patient groups to be included. Until then, we propose a combination of ultrasonography of the bladder and upper urinary tract, urinary cytology and urine sediment (erythrocytes) every 1-2 years. We recommend a surveillance programme for UC of the bladder and upper urinary tract for all MSH2 mutation carriers starting at the age of 40 , which is based on the youngest Lynch syndrome patient with bladder cancer reported in the literature (age 40) and observed in our study (age 41). ${ }^{36}$ The top age limit of surveillance for UC can be similar to that of surveillance for colorectal cancer. Surveillance should not be limited to families with a history of UC, because in our study clustering of urinary tract cancer was only observed in five families, while 19 patients had a negative family history of urinary tract cancer.

In conclusion, our data suggest that in addition to upper urinary tract cancer, urothelial cancer of the urinary bladder is part of the Lynch syndrome tumour spectrum. Carriers of an MSH2 mutation are particularly at increased risk of urinary tract cancer including cancer of the bladder. In these cases we consider surveillance necessary.

Acknowledgements We would like to thank Irene Reimerink and Marsha Voorendt (genetic counselors), Dr Ernie Bongers (clinical geneticist), Riki Willems, Monique Link, Monique Goossens, Sandra Hendriks-Cornelissen and Evelien Hoenselaar (technical assistance).

Competing interests None.

Provenance and peer review Not commissioned; externally peer reviewed.

\section{REFERENCES}

1. Aarnio M, Mecklin JP, Aaltonen LA, Nystrom-Lahti M, Jarvinen HJ. Life-time risk of different cancers in hereditary non-polyposis colorectal cancer (HNPCC) syndrome. Int J Cancer 1995;64:430-3.

2. Vasen HF, Stormorken A, Menko FH, Nagengast FM, Kleibeuker JH, Griffioen G, Taal BG, Moller P, Wijnen JT. MSH2 mutation carriers are at higher risk of cancer than MLH1 mutation carriers: a study of hereditary nonpolyposis colorectal cancer families. J Clin Oncol 2001;19:4074-80.

3. Dunlop MG, Farrington SM, Carothers AD, Wyllie AH, Sharp L, Burn J, Liu B, Kinzler KW, Vogelstein B. Cancer risk associated with germline DNA mismatch repair gene mutations. Hum Mol Genet 1997;6:105-10.

4. Hendriks YM, Wagner A, Morreau H, Menko F, Stormorken A, Quehenberger F, Sandkuijl L, Moller P, Genuardi M, Van HH, Tops C, van PM, Verkuijlen P, Kenter G, Van MA, Meijers-Heijboer H, Tan GB, Breuning MH, Fodde R, Wijnen JT, BrockerVriends $\mathrm{AH}$, Vasen $\mathrm{H}$. Cancer risk in hereditary nonpolyposis colorectal cancer due to MSH6 mutations: impact on counseling and surveillance. Gastroenterology 2004;127:17-25.

5. Quehenberger $\mathbf{F}$, Vasen HF, van Houwelingen HC. Risk of colorectal and endometrial cancer for carriers of mutations of the hMLH1 and hMSH2 gene: correction for ascertainment. J Med Genet 2005;42:491-6.

6. Sijmons RH, Kiemeney LA, Witjes JA, Vasen HF. Urinary tract cancer and hereditary nonpolyposis colorectal cancer: risks and screening options. J Urol 1998:160:466-70.

7. Lynch HT, Taylor RJ, Lynch JF, Knezetic JA, Barrows A, Fodde R, Wijnen J, Wagner A. Multiple primary cancer, including transitional cell carcinoma of the upper 
uroepithelial tract in a multigeneration HNPCC family: molecular genetic, diagnostic, and management implications. Am J Gastroenterol 2003;98:664-70

8. Vasen HF, Wijnen JT, Menko FH, Kleibeuker JH, Taal BG, Griffioen G, Nagengast FM, Meijers-Heijboer EH, Bertario L, Varesco L, Bisgaard ML, Mohr J, Fodde R, Khan PM. Cancer risk in families with hereditary nonpolyposis colorectal cancer diagnosed by mutation analysis. Gastroenterology 1996:110:1020-7.

9. Watson $\mathbf{P}$, Lynch HT. Extracolonic cancer in hereditary nonpolyposis colorectal cancer. Cancer 1993;71:677-85.

10. Baglietto L, Lindor NM, Dowty JG, White DM, Wagner A, Gomez Garcia EB, Vriends $\mathrm{AH}$, Cartwright NR, Barnetson RA, Farrington SM, Tenesa A, Hampel H, Buchanan D, Arnold S, Young J, Walsh MD, Jass J, Macrae F, Antill Y, Winship IM, Giles GG, Goldblatt J, Parry S, Suthers G, Leggett B, Butz M, Aronson M, Poynter JN, Baron JA, Le ML, Haile R, Gallinger S, Hopper JL, Potter J, de la Chapelle A, Vasen HF, Dunlop MG, Thibodeau SN, Jenkins MA. Risks of Lynch Syndrome Cancers for MSH6 Mutation Carriers. J Natl Cancer Inst 2010;102:193-201.

11. Vasen HF, Moslein G, Alonso A, Bernstein I, Bertario L, Blanco I, Burn J, Capella G, Engel C, Frayling I, Friedl W. Hes FJ, Hodgson S, Mecklin JP, Moller P, Nagengast F, Parc Y, Renkonen-Sinisalo L, Sampson JR, Stormorken A, Wijnen J. Guidelines for the clinical management of Lynch syndrome (hereditary non-polyposis cancer). J Med Genet 2007:44:353-62

12. Watson P, Vasen HF, Mecklin JP, Bernstein I, Aarnio M, Jarvinen HJ, Myrhoj T, Sunde L, Wijnen JT, Lynch HT. The risk of extra-colonic, extra-endometrial cancer in the Lynch syndrome. Int J Cancer 2008;123:444-9.

13. Aarnio M, Sankila R, Pukkala E, Salovaara R, Aaltonen LA, de la Chapelle A, Peltomaki P, Mecklin JP, Jarvinen HJ. Cancer risk in mutation carriers of DNAmismatch-repair genes. Int J Cancer 1999;81:214-18.

14. Maul JS, Warner NR, Kuwada SK, Burt RW, Cannon-Albright LA. Extracolonic cancers associated with hereditary nonpolyposis colorectal cancer in the Utah Population Database. Am J Gastroenterol 2006;101:1591-6.

15. Parc Y, Boisson C, Thomas G, Olschwang S. Cancer risk in 348 French MSH2 or MLH1 gene carriers. J Med Genet 2003:40:208-13.

16. Geary J, Sasieni P, Houlston R, Izatt L, Eeles R, Payne SJ, Fisher S, Hodgson SV Gene-related cancer spectrum in families with hereditary non-polyposis colorectal cancer (HNPCC). Fam Cancer 2008;7:163-72.

17. Lin KM, Shashidharan M, Thorson AG, Ternent CA, Blatchford GJ, Christensen MA, Watson P, Lemon SJ, Franklin B, Karr B, Lynch J, Lynch HT. Cumulative incidence of colorectal and extracolonic cancers in MLH1 and MSH2 mutation carriers of hereditary nonpolyposis colorectal cancer. J Gastrointest Surg 1998;2:67-71.

18. Bermejo JL, Eng C, Hemminki K. Cancer characteristics in Swedish families fulfilling criteria for hereditary nonpolyposis colorectal cancer. Gastroenterology 2005;129:1889-99.

19. Gylling AH, Nieminen $\Pi$, Abdel-Rahman WM, Nuorva K, Juhola M, Joensuu El, Jarvinen HJ, Mecklin JP, Aarnio M, Peltomaki PT. Differential cancer predisposition in Lynch syndrome: insights from molecular analysis of brain and urinary tract tumors. Carcinogenesis 2008:29:1351-9.

20. Hartmann A, Zanardo L, Bocker-Edmonston T, Blaszyk H, Dietmaier W, Stoehr R, Cheville JC, Junker K, Wieland W, Knuechel R, Rueschoff J, Hofstaedter F, Fishel R. Frequent microsatellite instability in sporadic tumors of the upper urinary tract. Cancer Res 2002;62:6796-802.

21. Umar A, Boland CR, Terdiman JP, Syngal S, de la Chapelle A, Ruschoff J, Fishel R, Lindor NM, Burgart LJ, Hamelin R, Hamilton SR, Hiatt RA, Jass J, Lindblom A, Lynch HT, Peltomaki P, Ramsey SD, Rodriguez-Bigas MA, Vasen HF, Hawk ET, Barrett JC, Freedman AN, Srivastava S. Revised Bethesda Guidelines for hereditary nonpolyposis colorectal cancer (Lynch syndrome) and microsatellite instability. J Natl Cancer Inst 2004;96:261-8.
22. Kiemeney LA, Lemmers FA, Verhoeven RH, Aben KK, Honing C, de NJ, Peeters PH, Visser 0, Vlems FA. [The risk of cancer in the Netherlands] (In Dutch). Ned Tijdschr Geneeskd 2008;152:2233-41.

23. Kets CM, van Krieken JH, Hebeda KM, Wezenberg SJ, Goossens M, Brunner HG, Ligtenberg MJ, Hoogerbrugge N. Very low prevalence of germline MSH6 mutations in hereditary non-polyposis colorectal cancer suspected patients with colorectal cancer without microsatellite instability. Br J Cancer 2006;95:1678-82.

24. de Jong AE, van PM, Hendriks $Y$, Tops C, Wijnen J, Ausems MG, MeijersHeijboer $H$, Wagner A, van Os TA, Brocker-Vriends AH, Vasen HF, Morreau H. Microsatellite instability, immunohistochemistry, and additional PMS2 staining in suspected hereditary nonpolyposis colorectal cancer. Clin Cancer Res 2004; 10:972-80

25. Overbeek LI, Ligtenberg MJ, Willems RW, Hermens RP, Blokx WA, Dubois SV, van der Linden H, Meijer JW, Mlynek-Kersjes ML, Hoogerbrugge N, Hebeda KM, van Krieken $\mathrm{JH}$. Interpretation of immunohistochemistry for mismatch repair proteins is only reliable in a specialized setting. Am J Surg Pathol 2008;32:1246-51.

26. Jarvinen HJ, Aarnio M, Mustonen H, Aktan-Collan K, Aaltonen LA, Peltomaki $P$, de la Chapelle A, Mecklin JP. Controlled 15-year trial on screening for colorectal cancer in families with hereditary nonpolyposis colorectal cancer. Gastroenterology 2000:118:829-34.

27. Vasen HF, Watson P, Mecklin JP, Lynch HT. New clinical criteria for hereditary nonpolyposis colorectal cancer (HNPCC, Lynch syndrome) proposed by the International Collaborative group on HNPCC. Gastroenterology 1999;116:1453-6.

28. Plaschke J, Engel C, Kruger S, Holinski-Feder E, Pagenstecher C, Mangold E, Moeslein G, Schulmann K, Gebert J, von Knebel DM, Ruschoff J, Loeffler M, Schackert HK. Lower incidence of colorectal cancer and later age of disease onset in 27 families with pathogenic MSH6 germline mutations compared with families with MLH1 or MSH2 mutations: the German Hereditary Nonpolyposis Colorectal Cancer Consortium. J Clin Oncol 2004;22:4486-94.

29. Hampel H, Stephens JA, Pukkala E, Sankila R, Aaltonen LA, Mecklin JP, de la Chapelle A. Cancer risk in hereditary nonpolyposis colorectal cancer syndrome: later age of onset. Gastroenterology 2005;129:415-21.

30. Lindor NM, Petersen GM, Hadley DW, Kinney AY, Miesfeldt S, Lu KH, Lynch P, Burke W. Press N. Recommendations for the care of individuals with an inherited predisposition to Lynch syndrome: a systematic review. JAMA 2006;296:1507-17.

31. Lokeshwar VB, Habuchi T, Grossman HB, Murphy WM, Hautmann SH, Hemstreet GP III, Bono AV, Getzenberg RH, Goebell P, Schmitz-Drager BJ, Schalken JA, Fradet $Y$, Marberger M, Messing E, Droller MJ. Bladder tumor markers beyond cytology: International Consensus Panel on bladder tumor markers. Urology 2005;66(6 Suppl 1):35-63.

32. Myrhoj T, Andersen MB, Bernstein I. Screening for urinary tract cancer with urine cytology in Lynch syndrome and familial colorectal cancer. Fam Cancer 2008; 7:303-7

33. Wakui $\mathbf{M}$, Shiigai T. Urinary tract cancer screening through analysis of urinary red blood cell volume distribution. Int J Urol 2000:7:248-53.

34. Koornstra JJ, Mourits MJ, Sijmons RH, Leliveld AM, Hollema H, Kleibeuker JH. Management of extracolonic tumours in patients with Lynch syndrome. Lancet Oncol 2009;10:400-8.

35. Babjuk M, Oosterlinck W, Sylvester R, et al. European Association of Urology (EAU) guidelines on non-muscle-invasive urothelial carcinoma of the bladder. Eur Urol 2008;54:303-14

36. Hirata K, Kanemitsu S, Nakayama $Y$, Nagata N, Itoh H, Ohnishi H, Ishikawa $H_{\text {, }}$ Furukawa $\mathrm{Y}$. A novel germline mutation of $\mathrm{MSH} 2$ in a hereditary nonpolyposis colorectal cancer patient with liposarcoma. Am J Gastroenterol 2006;101:193-6. 